\title{
The significant gap between international standards and stroke management practices at Queen Elizabeth Central Hospital (Malawi): An audit report
}

\author{
Yohane Gadama ${ }^{1,2}, \dagger$, Joseph Kamtchum-Tatuene ${ }^{1,3}, \dagger$, Laura Benjamin ${ }^{1,2,4}$, Tamara Phiri ${ }^{5}$, Henry C \\ Mwandumba ${ }^{1,6}$
}

1. Malawi-Liverpool-Wellcome Trust Clinical Research Programme, College of Medicine, P.O. Box 30096, Chichiri, Blantyre 3, Malawi

2. Institute of Neurology, University College London, London, UK

3. Neuroscience and Mental Health Institute, Faculty of Medicine and Dentistry, University of Alberta, Edmonton, Canada

4. Institute of Infection and Global Health, University of Liverpool, UK

5. Department of Medicine, Queen Elizabeth Central Hospital, P.O. Box 95, Blantyre, Malawi

6. Department of Clinical Sciences, Liverpool School of Tropical Medicine, Liverpool, UK

\section{Background}

\section{Abstract}

The Queen Elizabeth Central Hospital (QECH) is preparing to set up the first stroke unit in Blantyre, Malawi. We conducted this audit to assess current stroke management practices and outcomes at QECH and identify priority areas for intervention.

\section{Methods}

From April to June 2018, we prospectively enrolled patients with acute stroke and collected data on clinical presentation, cardiovascular risk factors, investigations and interventions, in-hospital outcomes, and follow-up plans after discharge. The American Heart Association/American Stroke Association (AHA/ASA) guidelines were used as the standard of care for comparison.

Results

Fifty patients with acute stroke were enrolled (46\% women, 54\% men). The mean age was 63.1 years (95\% CI: 59.7-66.6). The diagnosis of stroke was based on the World Health Organization criteria. The diagnosis was made within 24 hours of admission in 19 patients $(38 \%)$. Acute revascularisation therapy was not available. Forty-eight patients $(96 \%)$ had their vital signs checked at baseline and $<10 \%$ had their vital signs checked more than three times within the first 24 hours. Essential blood tests including random blood sugar (RBS), full blood count (FBC), urea/creatinine, and lipid profiles were performed in 72\%, 68\%, 48\%, and 4\%, respectively. An electrocardiogram was performed on 34 patients (68\%). Blood pressure on admission was $>140 / 90 \mathrm{mmHg}$ in 34 patients $(68 \%)$, including 4 with values $>220 / 120 \mathrm{mmHg}$. Nine patients had an RBS $>10 \mathrm{mmol} / \mathrm{L}$ and four received insulin. Prophylaxis for deep venous thrombosis was offered to 12 patients $(24 \%)$. Aspiration pneumonia was reported in 16 patients $(32 \%)$ and was the most common hospital complication. The mean duration of hospitalisation was 10.4 days (95\% CI: 5.6-15.2), and case fatality was $18 \%$. The modified Rankin scale at discharge was $\leq 2$ in $32 \%$ of patients. Only four patients ( $8 \%$ ) were transferred to a rehabilitation centre. At the time of discharge, only $32 \%$ of patients received education on stroke.

Conclusion

Acute stroke care is less than optimal in this setting. Simple interventions such as reducing the delay in making a stroke diagnosis, early swallow assessments, and closer monitoring of vital signs could make a significant difference in stroke outcome. Furthermore, treating cardiovascular risk factors and setting up health education programmes to improve secondary prevention represent key priorities.

\section{Key Words}

Stroke, diagnosis, management, outcome, low- to middle-income, Africa

\section{Introduction}

Stroke is one of the major public health concerns and the second leading cause of death globally ${ }^{1}$. Based on current trends, the burden of stroke is expected to double by 20302. At a time when the incidence of stroke is declining in highincome countries, it is increasing in low- and middle-income countries, especially in Africa ${ }^{2}$. This increase is not surprising given that Africa is undergoing an epidemiological transition driven by socio-demographic and lifestyle changes ${ }^{3,4}$. The latter include increased consumption of unhealthy diets, sedentary lifestyle, and excessive alcohol intake and smoking. Furthermore, the high prevalence of HIV infection in subSaharan Africa is also a driver of stroke incidence, especially in young adults ${ }^{5,6}$. The burden of stroke is compounded by the scarcity of resources and the absence or inadequacy of treatment and prevention guidelines ${ }^{4,7}$.
Malawi is not exempt from the challenges experienced by other African countries in the optimal management of patients with stroke. Queen Elizabeth Central Hospital $(\mathrm{QECH})$, the country's largest tertiary health facility, does not have specialist neurology or stroke services and has limited capacity for radiological imaging ${ }^{8}$. Patients with stroke are managed on the general medical wards by internal medicine physicians. Through a recent collaboration with University College London (UCL), QECH is preparing to open a stroke unit (https://malawistrokeunit.org/) where patients with stroke will be managed by a specialist team ${ }^{9}$. Successful implementation of this initiative requires identification of key priority areas for intervention, which will facilitate the efficient deployment of plans tailored to the patients' needs. However, current stroke management practices and outcomes at the QECH are poorly documented. We aim to 
address this knowledge gap by conducting an audit to collect data on stroke management and outcomes at QECH and identify key areas for improvement. Being the first audit conducted at QECH, the findings will form the basis of future studies to assess the impact of the stroke unit on patient care and outcomes and decisions on future resource allocation.

\section{Methods}

\section{Selection of patients and data collection}

From 1 April to 30 June 2018, we prospectively enrolled all patients aged 18 years and above diagnosed with an acute stroke who presented at QECH in Blantyre within 14 days of onset of symptoms. QECH is Malawi's largest referral and teaching hospital which receives patients from surrounding district hospitals, health centres, and private healthcare facilities. The hospital has an official bed capacity of 1350 but usually the number of patients admitted exceeds this capacity (personal communication from Mr Chisi, QECH hospital administrator). The diagnosis of stroke was made on admission by the attending clinician. Patients were excluded if they were subsequently diagnosed with a nonvascular cause for their neurological deficit.

A pre-designed case report form was used to collect data on patients' demographics, clinical presentation, cardiovascular risk factors, investigations performed and their results, inpatient care plan, in-hospital outcomes, and follow-up plans after discharge. Data were exclusively obtained through a review of medical records, except when assessing the overall satisfaction with care before discharge. This was done to minimise the interactions between the auditors, patients and health personnel. The auditors were formally instructed to avoid interfering with management.

\section{Data management and analysis}

Data were entered in Research Electronic Data Capture software (REDCap consortium, Vanderbilt University, TN, USA), then cleaned and validated by two independent data officers. Data analysis was performed using STATA (version 13, StataCorp LLC, College Station, TX, USA). Participants' demographic and clinical data were summarised as proportions or means with $95 \%$ confidence intervals for categorical or continuous variables, respectively. The American Heart Association/American Stroke Association (AHA/ASA) guidelines ${ }^{10}$ were used as the standard to interpret the data and assess the quality of current stroke care in Malawi. Although written for high-income settings, these guidelines incorporate the latest evidence in clinical stroke care and provide clear, specific, and quantifiable criteria for the management of acute stroke.

\section{Ethical considerations}

All patients or their guardians provided written informed consent to participate in the audit, which was approved by the University of Malawi, College of Medicine Research Ethics Committee (COMREC) (Approval number P.02/18/2361) and the senior management team of QECH.

\section{Results}

\section{Baseline characteristics of the participants}

We enrolled 50 patients diagnosed with stroke, including 23 women (46\%) and 27 men (54\%). Seventy-five per cent of the patients were referred from health centres within Blantyre district while the remaining $25 \%$ were self-referrals from surrounding districts. The mean age of our study participants was 63.1 (95\% CI, 59.7-66.6). More than half of the patients, $27(54 \%)$, enrolled in this study had a primary school education $(27 ; 54 \%)$. Fifteen participants (30\%) had a salaried job while the others were either in informal employment $(26 ; 52 \%)$ or not working at all $(9 ; 18 \%)$.

Twenty-four patients $(48 \%)$ reached the hospital within 24 hours of stroke onset. There was no age or sex difference between patients arriving at the hospital within 24 hours of stroke onset and those arriving 24 hours after stroke onset. In these subgroups, the mean age was 61.8 and $64.4(\mathrm{P}=0.44)$ while the proportion of women was 43.4 and $56.5(\mathrm{P}=0.58)$, respectively.

Table 1. Summary of the demographics and clinical characteristics of the study participants

\begin{tabular}{|l|l|}
\hline Characteristic & Frequency \\
\hline Sex & \\
\hline Females & $23(46 \%)$ \\
\hline Males & $27(54 \%)$ \\
\hline Age in years & \\
\hline Mean & $63.1(95 \%$ Cl: $59.7-66.6)$ \\
\hline Education level & \\
\hline None & $9(18 \%)$ \\
\hline Primary & $18(36 \%)$ \\
\hline Secondary & $18(36 \%)$ \\
\hline Tertiary & $4(8 \%)$ \\
\hline Income status & \\
\hline Fixed monthly income & $15(30 \%)$ \\
\hline Variable daily income & $11(22 \%)$ \\
\hline Occasional income & $15(30 \%)$ \\
\hline No income & $9(18 \%)$ \\
\hline Residence & \\
\hline Within Blantyre & $37(75 \%)$ \\
\hline Outside Blantyre & $13(25 \%)$ \\
\hline Stroke risk factors & \\
\hline Hypertension & $25(50 \%)$ \\
\hline Diabetes mellitus & $10(20 \%)$ \\
\hline Smoking & $13(26 \%)$ \\
\hline Alcohol consumption & $14(28 \%)$ \\
\hline History of heart disease & $0(0 \%)$ \\
\hline Physical inactivity & $40(80 \%)$ \\
\hline Personal history of stroke & $11(22 \%)$ \\
\hline Family history of stroke & $15(30 \%)$ \\
\hline Common presenting symptoms & \\
\hline Motor deficit (upper or lower & $44(88 \%)$ \\
\hline limbs) & $29(58 \%)$ \\
\hline Altered consciousness & $15(30 \%)$ \\
\hline Altered speech & 0 \\
\hline Altered sensation & $16(32 \%)$ \\
\hline Facial asymmetry & $(4 \%)$ \\
\hline Altered balance & \\
\hline & prenting symptoms \\
\hline
\end{tabular}

aThe presenting symptoms are listed as they were recorded in the patients' files; some patients could have more than one presenting symptom 
Table 2. Quantification of the gap between selected ASA/AHA recommendations current practice at QECH

\begin{tabular}{|c|c|c|}
\hline AHA/ASA recommendation & Current practice at QECH & Comments \\
\hline $\begin{array}{l}\text { Stroke severity should be ascertained, } \\
\text { preferably using the NIHSS scale. }\end{array}$ & Not done & \\
\hline $\begin{array}{l}\text { Patients with acute stroke should receive } \\
\text { brain imaging evaluation on arrival to } \\
\text { hospital (NCCT scan ideal). }\end{array}$ & Not available & $\begin{array}{l}\text { At the time of this audit, QECH did not } \\
\text { have a functioning CT scanner. Only three } \\
\text { patients had an MRI on day } 7,8 \text { and } 9 \text { post- } \\
\text { admission. }\end{array}$ \\
\hline $\begin{array}{l}\text { Vital signs check done on admission and at } \\
\text { least every } 4 \text { hours during the first } 48 \text { hours. }\end{array}$ & $\begin{array}{l}\text { Admission check: BP } \\
(98 \%), \text { temperature }(82 \%) \\
\text { pulse rate }(98 \%) \text {, oxygen } \\
\text { saturation }(62 \%)\end{array}$ & $\begin{array}{l}\text { A check was not done every } 4 \text { hours, even } \\
\text { for patients managed in HDU. }\end{array}$ \\
\hline IV thrombolysis - AIS, less than 4.5 hours. & Not available & \multirow{2}{*}{$\begin{array}{l}\text { No resources to allow for these acute } \\
\text { interventions. The time window could allow } \\
\text { mechanical thrombectomy in up to } 48 \% \text { of } \\
\text { patients (who reached the hospital within } 24 \\
\text { hours of symptoms onset). }\end{array}$} \\
\hline $\begin{array}{l}\text { Mechanical thrombectomy - AIS, up to } 24 \\
\text { hours. }\end{array}$ & Not available & \\
\hline $\begin{array}{l}\text { Blood glucose should be checked in all } \\
\text { patients. }\end{array}$ & $36(72 \%)$ checked & \\
\hline $\begin{array}{l}\text { Blood pressure control } \\
\text { BP >220/120 mmHg - urgent lowering by } \\
15 \% \\
\text { BP <220/120 mmHg - not to be treated in } \\
\text { first } 48-72 \text { hours }\end{array}$ & $\begin{array}{l}4 \text { patients with BP } \\
>220 / 130 \\
3 \text { had urgent lowering } \\
12 / 18(67 \%) \text { received } \\
\text { drugs }\end{array}$ & $\begin{array}{l}\text { There were variations in the management of } \\
\text { raised BP among clinicians. Some allowed } \\
\text { a raised BP in the first } 48 \text { hours while others } \\
\text { treated it. }\end{array}$ \\
\hline $\begin{array}{l}\text { Aspirin to be administered in AIS patients } \\
\text { within 24-48 hours after onset. }\end{array}$ & $38(76 \%)$ received & $\begin{array}{l}\text { Among those who received aspirin, all } \\
\text { had it orally, regardless of the level of } \\
\text { consciousness. Standard dose: } 75 \mathrm{mg} \\
\text { Aspirin is only available in oral form in the } \\
\text { hospital. }\end{array}$ \\
\hline Urgent anticoagulation not recommended. & Adhered to & $\begin{array}{l}\text { No patient received anticoagulation in the } \\
\text { first } 72 \text { hours. }\end{array}$ \\
\hline $\begin{array}{l}\text { Patients to be managed in specialised } \\
\text { stroke units. }\end{array}$ & Not available & \\
\hline $\begin{array}{l}\text { Airway support and ventilatory assistance } \\
\text { recommended for patients who have } \\
\text { decreased consciousness or bulbar } \\
\text { dysfunction (maintain oxygen saturation } \\
>94 \% \text { ). }\end{array}$ & $\begin{array}{l}9 / 29(31 \%) \text { received } \\
\text { oxygen }\end{array}$ & $\begin{array}{l}\text { Patients could only receive supplemental } \\
\text { oxygen when admitted to the HDU. There is } \\
\text { limited bed space in the HDU for all medical } \\
\text { patients. }\end{array}$ \\
\hline $\begin{array}{l}\text { Starting or restarting antihypertensive } \\
\text { therapy during hospitalisation in patients } \\
\text { with blood pressure }>140 / 90 \mathrm{mmHg} \text { who } \\
\text { are neurologically stable is safe and is } \\
\text { reasonable. }\end{array}$ & $\begin{array}{l}98 \% \text { of hypertensive } \\
\text { patients received }\end{array}$ & $\begin{array}{l}\text { The choice of antihypertensive drug to } \\
\text { prescribe is determined by what is in stock } \\
\text { in the pharmacy. }\end{array}$ \\
\hline $\begin{array}{l}\text { Sources of hyperthermia (temperature } \\
>38^{\circ} \mathrm{C} \text { ) should be identified and treated. } \\
\text { Antipyretic medications should be } \\
\text { administered to lower temperature in } \\
\text { hyperthermic patients with stroke. }\end{array}$ & $\begin{array}{l}5 / 5(100 \%) \text { with fever } \\
\text { treated }\end{array}$ & $\begin{array}{l}\text { Paracetamol was prescribed as an } \\
\text { antipyretic. FBC, chest X-ray, and rapid } \\
\text { malaria tests were done to investigate fever. }\end{array}$ \\
\hline $\begin{array}{l}\text { Aim to maintain normal blood sugar. Treat } \\
\text { hyperglycaemia and hypoglycaemia. }\end{array}$ & $\begin{array}{l}4 / 11(36 \%) \text { received insulin } \\
\text { to treat hyperglycaemia }\end{array}$ & $\begin{array}{l}\text { Uncontrolled hyperglycaemia was a } \\
\text { common complication observed. }\end{array}$ \\
\hline $\begin{array}{l}\text { Dysphagia screening before the patient } \\
\text { begins eating, drinking, or receiving oral } \\
\text { medications. }\end{array}$ & Not done & $\begin{array}{l}\text { Level of consciousness seemed to have } \\
\text { guided clinicians and nurses to insert NGT. }\end{array}$ \\
\hline $\begin{array}{l}\text { In immobile patients with stroke and without } \\
\text { contraindications, intermittent pneumatic } \\
\text { compression is recommended to reduce the } \\
\text { risk of DVT. }\end{array}$ & Not available & $\begin{array}{l}\text { DVT prophylaxis offered to } 12 \text { patients. } \\
\text { The majority }(n=9) \text { received LMWH ( } 2 \text { had } \\
\text { standard heparin and } 1 \text { stockings). In all } 12 \\
\text { patients, prophylaxis was started } 48 \text { hours } \\
\text { after admission. }\end{array}$ \\
\hline $\begin{array}{l}\text { Routine screening and treatment of post- } \\
\text { stroke depression. }\end{array}$ & Not done & \\
\hline
\end{tabular}


Table 2 Cont....

\begin{tabular}{|c|c|c|}
\hline $\begin{array}{l}\text { Physiotherapy to be started in-hospital } \\
\text { ideally after } 24 \text { hours. }\end{array}$ & $\begin{array}{l}60 \% \text { received } \\
\text { physiotherapy } \\
2 \text { patients started within } \\
48 \text { hours }\end{array}$ & $\begin{array}{l}\text { Physiotherapy students provided many } \\
\text { services to patients. There was a sharp } \\
\text { decline in physiotherapy sessions soon after } \\
\text { the students went on holiday. }\end{array}$ \\
\hline $\begin{array}{l}\text { Cardiac monitoring to screen for atrial } \\
\text { fibrillation/serious cardiac arrhythmias. To be } \\
\text { performed for at least the first } 24 \text { hours. }\end{array}$ & $\begin{array}{l}34(68 \%) \text { had an ECG } \\
7 / 34 \text { had it on the first day } \\
\text { of admission }\end{array}$ & $\begin{array}{l}\text { ECG is usually performed by one officer } \\
\text { within the medical department who has } \\
\text { other duties as well. No prolonged cardiac } \\
\text { monitoring is done. }\end{array}$ \\
\hline $\begin{array}{l}\text { Diabetes screening (HbA1c usage } \\
\text { recommended). }\end{array}$ & Not done & QECH rely on RBS for diabetes screening. \\
\hline $\begin{array}{l}\text { High-dose statin therapy should be initiated } \\
\text { or continued as first-line therapy in women } \\
\text { and men } \leq 75 \text { years of age who have clinical } \\
\text { ASCVDa unless contraindicated. }\end{array}$ & $4 \%$ were prescribed statins & $\begin{array}{l}\text { QECH pharmacy does not stock statins. } \\
\text { Patients had to purchase these drugs from } \\
\text { private pharmacies. }\end{array}$ \\
\hline $\begin{array}{l}\text { In-hospital counselling for smoking } \\
\text { cessation. }\end{array}$ & Not done & $\begin{array}{l}\text { Not formally done. Some clinicians would } \\
\text { discuss it with patients while doing rounds. }\end{array}$ \\
\hline $\begin{array}{l}\text { Patient education about stroke is } \\
\text { recommended. }\end{array}$ & $32 \%$ had stroke education & $\begin{array}{l}\text { Medical students/student nurses were } \\
\text { mostly involved with patients that received } \\
\text { education. Not a structured education. }\end{array}$ \\
\hline
\end{tabular}

AIS, acute ischaemic stroke; AHA, American Heart Association; ASA, American Stroke Association; ASCVD, atherosclerotic cardiovascular disease; BP, blood pressure; DVT, deep venous thrombosis; ECG, electrocardiogram; FBC, full blood count; HbA1c, glycated haemoglobin; HDU, high dependency unit; LMWH, low molecular weight heparin; NCCT, non-contrast CT; NGT, nasogastric tubes; NIHSS, National Institutes of Health Stroke Scale; QECH, Queen Elizabeth Central Hospital; RBS, random blood sugar.

aClinical ASCVD: acute coronary syndromes, history of myocardial infarction, stable or unstable angina, coronary or other arterial revascularisation, stroke, transient ischaemic attack (TIA), or peripheral arterial disease presumed to be of atherosclerotic origin.

The main cardiovascular risk factors identified were physical inactivity $(80 \%)$ and hypertension (50\%). Other reported risk factors were diabetes mellitus $(20 \%)$, current smoking $(26 \%)$, ongoing alcohol consumption (28\%), previous history of stroke $(22 \%)$ and family history of stroke $(30 \%)$. The most common presenting symptoms were limb weakness $(88 \%)$, altered level of consciousness (58\%), facial asymmetry $(32 \%)$ and aphasia (30\%). Table 1 summarises the demographic and clinical characteristics of the study participants.

\section{Diagnosis and destination}

None of the patients were assessed for stroke severity using the National Institutes of Health Stroke Scale (NIHSS) (http://www.nihstrokescale.org/). In all patients, the diagnosis of stroke was based on the clinical presentation. Only three patients $(6 \%)$ subsequently had MRI scans of the brain on day 7,8 and 9 post-admission, respectively. The diagnosis of stroke was made within 24 hours in 19 patients (38\%), between 24 and 72 hours in 25 patients (50\%), and over 72 hours in 6 patients $(12 \%)$. Forty-one patients $(82 \%)$ were admitted to the general medical wards, while the remaining nine $(18 \%)$ were admitted to the High Dependency Unit (HDU). Of the 29 patients (58\%) who had a reduced level of consciousness, only nine were admitted to the HDU and received supplemental oxygen therapy. Patients in the general medical wards did not receive oxygen. Table 2 summarises the differences between the management of patients with stroke at QECH and the AHA/ASA guidelines.

\section{Monitoring and investigations}

On admission, blood pressure was checked in 48 patients $(96 \%)$, temperature in 41 patients $(82 \%)$, and oxygen saturation in 31 patients $(62 \%)$. Only five patients $(10 \%)$ had their vital signs checked more than three times within the first 24 hours. None of the participants had dysphagia screening.
The random blood sugar (RBS), full blood count (FBC), urea/creatinine tests, and lipid profiles were performed in 36 (72\%), 34 (68\%), $24(48 \%)$ and two (4\%) patients, respectively. Two patients had liver function tests. Electrolytes and lipid profile tests were performed in a private laboratory since these tests are not offered by the QECH core laboratory. Syphilis test (Venereal Disease Research Laboratory) and coagulation tests were not performed on any patient though the former is available at QECH. An electrocardiogram (ECG) was performed on 34 patients (68\%) but only seven patients had it within 24 hours of admission. Fifteen patients $(30 \%)$ had a cardiac ultrasound scan during their hospital stay, and none had an ultrasound examination of the cervical and intracranial arteries.

\section{Treatment}

Blood pressure on admission was $>140 / 90 \mathrm{mmHg}$ in $68 \%$ of patients, of whom four had values $>220 / 120 \mathrm{mmHg}$. A total of 17 patients received antihypertensive treatment within 48 hours of admission, including three patients with blood pressure $>220 / 120 \mathrm{mmHg}$. Nine patients had RBS $>10 \mathrm{mmol} / \mathrm{L}$ and four of them received insulin to correct hyperglycaemia. Low dose aspirin was administered orally to 38 patients $(76 \%)$, regardless of their level of consciousness. An intervention to prevent deep venous thrombosis (DVT) was administered in 12 patients (24\%), including low molecular weight heparin ( $\mathrm{n}=9$ ), unfractionated heparin ( $\mathrm{n}$ $=2$ ), or compression stockings $(n=1)$. The DVT prophylaxis was initiated after 48 hours in all 12 cases. Throughout their hospital stay, 30 patients $(60 \%)$ received physiotherapy with only two starting treatment within 48 hours. The mean number of physiotherapy sessions was 3.1 (95\% CI: 2.33.8) with only seven having four or more sessions. Acute revascularisation therapy (intravenous thrombolysis or endovascular thrombectomy), speech and language therapy, 
Table 3. Overview of the essential stroke service available at QECH according to the World Stroke Organisation roadmap

\begin{tabular}{|c|c|}
\hline $\begin{array}{l}\text { Component of acute stroke care/ service } \\
\text { required }\end{array}$ & Service availability \\
\hline \multicolumn{2}{|l|}{ Access to basic diagnostic services } \\
\hline Laboratory blood test & 1 \\
\hline Computed tomography (CT) & 0 \\
\hline Electrocardiogram (12 lead) & 1 \\
\hline CTA & 0 \\
\hline Doppler ultrasound & 0 \\
\hline \multicolumn{2}{|l|}{ Access to stroke trained health professionals } \\
\hline Access to nurses & 1 \\
\hline Neurologists & * \\
\hline Neurosurgeon & 1 \\
\hline Stroke physician & 0 \\
\hline Physician specialist & 1 \\
\hline $\begin{array}{l}\text { Access to stroke specialists through } \\
\text { telestroke modalities and teleradiology }\end{array}$ & * \\
\hline \multicolumn{2}{|c|}{$\begin{array}{l}\text { Access to acute inpatient stroke care, where admitted patients are } \\
\text { treated }\end{array}$} \\
\hline Stroke unit & 0 \\
\hline Scattered throughout hospital & 1 \\
\hline \multicolumn{2}{|c|}{$\begin{array}{l}\text { Protocols to guide acute stroke care based on best practice } \\
\text { guidelines }\end{array}$} \\
\hline Medical and nursing assessments & 0 \\
\hline Swallow screen & 0 \\
\hline Bladder and bowel continence & 0 \\
\hline Severity scoring (NIHSS) & 0 \\
\hline Skin integrity, DVT risk, mobility & 0 \\
\hline Interdisciplinary meetings weekly & 0 \\
\hline \multicolumn{2}{|l|}{ Early access to a rehabilitation specialist } \\
\hline Physiotherapists & 1 \\
\hline Speech therapists & 0 \\
\hline Occupational therapists & 1 \\
\hline $\begin{array}{l}\text { Patient and family education, skills training, } \\
\text { and involvement in care planning }\end{array}$ & 1 \\
\hline $\begin{array}{l}\text { Access to stroke prevention therapies } \\
\text { such as aspirin, lifestyle change } \\
\text { recommendations, blood pressure } \\
\text { management }\end{array}$ & 1 \\
\hline $\begin{array}{l}\text { Stroke training programmes for all levels of } \\
\text { healthcare providers }\end{array}$ & 0 \\
\hline
\end{tabular}

1 , service available; 0 , service unavailable;, , sporadic availability (visiting specialists who usually stay for short periods of time).

NB: This is a report of what is available at QECH, and not the extent to which the service is fully utilised in stroke patient care.

and occupational therapy were not offered to any of the patients as these treatments were not available.

\section{Outcome}

The most common in-hospital complications were aspiration pneumonia $(32 \%)$ and thromboembolic events $(24 \%)$. Other recorded complications were uncontrolled diabetes mellitus $(10 \%)$, urinary tract infection $(6 \%)$, malaria $(6 \%)$, and pressure sores $(4 \%)$. In-hospital death occurred in six patients $(12 \%)$ and three additional deaths occurred within 48 hours after discharge. The mean duration of hospitalisation was 10.4 days (95\% CI: 5.6-15.2). The modified Rankin scale $^{11}$, a measure of disability due to stroke, at discharge was 2 or lower in $32 \%$ of patients, $3-5$ in $56 \%$, and 6 in $12 \%$. Patients were mostly discharged to their homes and only four patients $(8 \%)$ were transferred to a rehabilitation centre. Half of the patients were given a follow-up appointment date on discharge. The time-to-first appointment ranged from 14 to 60 days. At the time of discharge, 35 patients $(70 \%)$ were aware of their diagnosis and only 16 patients $(32 \%)$ had received education on stroke. On a scale ranging from 0 to $10,64 \%$ of patients indicated a satisfaction score of 6 or higher with respect to the overall care received during their hospital stay.

\section{Discussion}

We conducted the audit to understand the management of patients with stroke at QECH and to inform the design and implementation of future initiatives to improve the care of patients with stroke in Malawi. To our knowledge, this is the first audit done to document stroke management practices at QECH. Our findings show that there are huge gaps between international evidence-based stroke management guidelines and current practices. Specifically, there is no consistent and structured implementation of any guidelines in the management of patients with stroke. While the absence of radiological imaging (e.g. CT scan), key laboratory services, and drugs are the main reasons for the poor uptake of evidence-based practice, the audit found underutilisation of available services at QECH.

Despite the poor referral system for patients in Malawi ${ }^{12}$, nearly half of the participants arrived at the hospital within the first 24 hours after the onset of symptoms. This highlights an opportunity to intervene early and thus reduce hospital death and disability. The absence of revascularisation therapies does not negate the opportunity to make a difference with a more systematic approach. An addressable area is the delay in making a stroke diagnosis and initiating in-hospital management. In the absence of a CT scan, a stroke diagnosis is made clinically, most often using the World Health Organization definition ${ }^{13,14}$. An experienced stroke physician will make the correct diagnosis in $85 \%$ of cases $^{15}$, but the accuracy is likely to be lower in less experienced clinicians who are at the forefront of managing patients with stroke when they present at QECH. However, with a focus on training, led by stroke experts within a stroke platform, there is an opportunity to improve the clinical acumen of less experienced clinicians in recognising stroke. Although we did not look specifically at former hospital encounters, a previous stroke study at QECH suggests that at least $10 \%$ of patients have stroke symptoms before their main stroke ${ }^{16}$. Therefore, training the accident and emergency staff to recognise minor stroke symptoms may improve riskstratification and help reduce the number of patients that may return and present with a more severe stroke.

Early clinical deterioration was found in more than half of the patients enrolled. In most cases, the deterioration was attributed to medical complications, with aspiration pneumonia being the most prevalent. This is likely because patients do not undergo dysphagia screening and very few patients with reduced level of consciousness are fed or receive drugs through nasogastric tubes. Formal and early evaluation of swallow function and appropriate dietary 
modifications in patients with stroke are crucial to prevent respiratory infections ${ }^{17,18}$. Early mobilisation and respiratory physiotherapy will also contribute to improve respiratory function and prevent pneumonia in an acute stroke setting ${ }^{19}$.

In recent years, physiotherapy services have improved in Malawi. More than half of the patients in this audit received physiotherapy during their hospital stay, although the rehabilitation was initiated late with a few sessions conducted during hospitalisation. Referral to a rehabilitation centre is facilitated by a physiotherapist upon request by the attending physician. In this audit, only four patients (8\%) were transferred to a rehabilitation centre at the end of acute stroke care. Strengthening multidisciplinary collaboration will help to get physiotherapists involved in the care process early and will facilitate appropriate triaging to the only rehabilitation unit in Blantyre.

The three deaths that occurred less than 2 days after discharge may suggest that patients are discharged before they are fit to go home. The mean length of stay was 10.4 days and is comparable to the average of 8.5 days found in a cross-sectional study conducted in four tertiary hospitals in Malawi ${ }^{20}$, but lower than the average 18.5 days reported by Heikinheimo et al. at the same hospital in $2012^{6}$. Earlier patient discharge is explained by the contrast between the increasing demand for hospitalisation and the limited number of medical beds at the hospital. This may also contribute to the overall mortality, which was $18 \%$ in this audit (including the three patients who died within 48 hours post-discharge). This is higher than the mortality rates observed in middle- to high-income countries ${ }^{21,22}$.

This audit revealed inconsistencies in many aspects of the management of patients with stroke, which is likely due to the absence of clear stroke management guidelines endorsed by local authorities. For example, some patients received antihypertensive medication within the first 48 hours of stroke onset despite having blood pressure below 220/120 $\mathrm{mmHg}$. It is not recommended to treat blood pressure below this threshold in the hyperacute phase, especially for ischaemic stroke ${ }^{10}$. In addition, only four patients received insulin out of the nine admitted with a blood glucose $>10$ $\mathrm{mmol} / \mathrm{L}$ whereas current AHA guidelines recommend that blood glucose levels should be maintained between 7.8 and $10 \mathrm{mmol} / \mathrm{L}^{10}$. Indeed, several studies have reported an association between hyperglycaemia and poor stroke outcomes ${ }^{23,24}$.

The last three decades have seen a major change and improvement in the management of stroke globally. Mechanical thrombectomy, intravenous thrombolysis, carotid endarterectomy, strict control of stroke risk factors, and managing patients in a stroke unit have proven effective in improving outcomes ${ }^{25-27}$. Given the current infrastructure and available resources ${ }^{8}$, QECH may not be able to implement these advanced interventions soon. However, setting up a stroke unit is feasible. Reducing the delay in making a diagnosis of stroke or starting rehabilitation, improving the monitoring of patients' vital signs, controlling cardiovascular risk factors, and setting up health education programmes to improve secondary stroke prevention represent priority needs that the stroke unit should address. The World Stroke Organisation (WSO) devised a road map for delivering acute stroke care that gives realistic expectations of what different settings should have in terms of both resources and services. From our experience in conducting this audit, and with data reported in a case report that reflected on the challenges of stroke management in resource-limited settings ${ }^{8}, \mathrm{QECH}$ falls in the 'minimum healthcare services' category of the WSO roadmap. Table 3 summarises the available resources and services at QECH. With such structural limitations, it would be expected that stroke care service provision would be suboptimal. Our audit found that the challenge of limited resources in this setting is further exacerbated by underutilisation of services that are already available. The laboratory has the capacity to perform FBC and kidney function tests, but these tests were not requested in all patients. These basic tests can have important clinical implications for stroke care. For instance, a low platelet count may raise suspicion of intracranial bleeding and would deter the administration of aspirin, whereas polycythaemia and leucocytosis may suggest a diagnosis of ischaemic stroke ${ }^{28,29}$.

The strengths of this audit are the prospective consecutive recruitment of patients and the rigorous collection and management of data. Its limitations include the small sample size due to time and budgetary constraints. Moreover, as the data collection was based mainly on chart reviews, we assumed that any intervention not documented was not performed. This assumption may not be true in some cases. Lastly, the audit lacked a follow-up component. Data on stroke mortality and functional outcome at 3 months and compliance with the follow-up calendar would have been useful to inform the planning of long-term care after discharge.

\section{Conclusion}

This audit has unveiled a significant gap between current stroke management practices at QECH and international evidence-based guidelines. Reducing the delay in making a stroke diagnosis, performing early dysphagia screening, improving the monitoring of patients' vital signs and the control of their cardiovascular risk factors, and setting up health education programmes to improve secondary prevention represent urgent and achievable goals. It is also important to optimise the use of available resources, strengthen the multidisciplinary approach in providing care to patients with stroke through regular meetings and continuing medical education programmes, and develop local care protocols with clearly defined evidence-based clinical pathways that are appropriate to this setting and the resources available.

\section{Acknowledgements}

We would like to thank all patients and their guardians who consented to take part in this audit. We also acknowledge the MLW data management team (especially Mr Clemens Masesa and Mrs Lumbani Makhaza) for their help with data entry and cleaning.

\section{Authors' contributions}

Study conception and design: YG, JKT, TP, LB, HCM; data collection and entry: YG; data analysis: JKT and YG; drafting manuscript: YG and JKT; critical revisions: YG, JKT, TP, LB, HCM.

\section{Funding}

JKT is grateful to the Wellcome Trust that supported his Clinical Research Fellowship in Malawi (grant number 106829/Z/15/Z). 


\section{Availability of data and materials}

The database of this audit is available for consultation or reuse on request to the corresponding author. Sharing of all or part of the database is subject to prior authorization by the University of Malawi College of Medicine Research Ethics Committee.

\section{Competing interests}

None to declare.

\section{References}

1. WHO. Top 10 causes of death $\neg$ Fact sheet $N^{\circ} 310$ [Internet]. Geneva: WHO Press; 2017 [updated January 2017; cited 2017 July 4]. Available from: http://www.who.int/entity/mediacentre/factsheets/fs310/en/ index.html\#.

2. Feigin VL, Forouzanfar MH, Krishnamurthi R, et al. Global and regional burden of stroke during 1990-2010: findings from the Global Burden of Disease Study 2010. Lancet. 2014;383(9913):245-54.

3. Allain TJ, Aston S, Mapurisa G, et al. Age related patterns of disease and mortality in hospitalised adults in Malawi. PLoS One. 2017;12(1):e0168368.

4. Baatiema L, Chan CKY, Sav A, Somerset S. Interventions for acute stroke management in Africa: a systematic review of the evidence. Syst Rev. 2017;6(1):213.

5. Benjamin LA, Bryer A, Emsley HC, Khoo S, Solomon T, Connor MD. HIV infection and stroke: current perspectives and future directions. Lancet Neurol. 2012;11(10):878-90.

6. Heikinheimo T, Chimbayo D, Kumwenda JJ, Kampondeni S, Allain TJ. Stroke outcomes in Malawi, a country with high prevalence of HIV: a prospective follow-up study. PLoS One. 2012;7(3):e33765.

7. Baatiema L, Otim M, Mnatzaganian G, Aikins AD, Coombes J, Somerset S. Towards best practice in acute stroke care in Ghana: a survey of hospital services. BMC Health Serv Res. 2017;17(1):108.

8. Gadama YG, Mwangalika G, Kinley LB, et al. Challenges of stroke management in resource-limited settings: a case-based reflection. Malawi Med J 2017;29(2):189-93.

9. Gadama Y, Kamtchum-Tatuene, Benjamin LA, Kamalo P, Mallewa M. Neurological letter from Malawi. Practical Neurology-BMJ. 2019;0:1-4. Available from: doi:10.1136/practneurol-2019-00222

10. Powers WJ, Rabinstein AA, Ackerson T, et al. 2018 guidelines for the early management of patients with acute ischemic stroke: a guideline for healthcare professionals from the American Heart Association/ American Stroke Association. Stroke. 2018;49(3):e46-110.

11. Broderick P, Adeoye O, Elm J. Evolution of the modified Rankin scale and its use in future stroke trials. Stroke. 2017;48:2007-12. Available from: doi: 10.1161/STROKEAHA.117.017866.

12. Makwero MT. Delivery of primary health care in Malawi. Afr J Prim Health Care Fam Med. 2018;10(1):e1-3.

13. Aho K, Harmsen P, Hatano S, Marquardsen J, Smirnov VE, Strasser T. Cerebrovascular disease in the community: results of a WHO collaborative study. Bull World Health Organ. 1980;58(1):113-30.

14. Sacco RL, Kasner SE, Broderick JP, et al. An updated definition of stroke for the 21 st century: a statement for healthcare professionals from the American Heart Association/American Stroke Association. Stroke. 2013;44(7):2064-89.

15. Benjamin LA, Corbett EL, Connor MD, et al. HIV, antiretroviral treatment, hypertension, and stroke in Malawian adults: a case-control study. Neurology. 2016;86(4):324-33.

16. Benjamin LA, Allain TJ, Mzinganjira $\mathrm{H}$, et al. The role of human immunodeficiency virus-associated vasculopathy in the etiology of stroke. J Infect Dis. 2017;216(5):545-53.

17. Bray BD, Smith CJ, Cloud GC, et al. The association between delays in screening for and assessing dysphagia after acute stroke, and the risk of stroke-associated pneumonia. J Neurol Neurosurg Psychiatry. 2017;88(1):25-30.

18. Hilker R, Poetter C, Findeisen N, et al. Nosocomial pneumonia after acute stroke: implications for neurological intensive care medicine. Stroke. 2003;34(4):975-81.

19. Menezes KK, Nascimento LR, Ada L, Polese JC, Avelino PR, Teixeira-Salmela LF. Respiratory muscle training increases respiratory muscle strength and reduces respiratory complications after stroke: a systematic review. J Physiother. 2016;62(3):138-44.

20. Chimatiro GL, Rhoda AJ, De Wit L. Stroke patients' outcomes and satisfaction with care at discharge from four referral hospitals in Malawi: a cross-sectional descriptive study in limited resource. Malawi Med J. 2018;30(3):152-8.

21. Ovbiagele B. Nationwide trends in in-hospital mortality among patients with stroke. Stroke. 2010;41(8):1748-54.

22. He Q, Wu C, Luo H, et al. Trends in in-hospital mortality among patients with stroke in China. PLoS One. 2014;9(3):e92763.

23. Gray CS, Hildreth AJ, Alberti GK, O'Connell JE; GIST Collaboration. Poststroke hyperglycemia: natural history and immediate management. Stroke. 2004;35(1):122-6.

24. Baird TA, Parsons MW, Phan T, et al. Persistent poststroke hyperglycemia is independently associated with infarct expansion and worse clinical outcome. Stroke. 2003;34(9):2208-14.

25. Catanese L, Tarsia J, Fisher M. Acute ischemic stroke therapy overview. Circ Res. 2017;120(3):541-58.

26. Evans A, Harraf F, Donaldson N, Kalra L. Randomized controlled study of stroke unit care versus stroke team care in different stroke subtypes. Stroke. 2002;33(2):449-55.

27. National Institute of Neurological Disorders and S rt-PA Stroke Study Group. Tissue plasminogen activator for acute ischemic stroke. N Engl J Med. 1995;333(24):1581-7.

28. Lee CD, Folsom AR, Nieto FJ, Chambless LE, Shahar E, Wolfe DA. White blood cell count and incidence of coronary heart disease and ischemic stroke and mortality from cardiovascular disease in African-American and White men and women: atherosclerosis risk in communities study. Am J Epidemiol. 2001;154(8):758-64.

29. Ohene-Frempong K, Weiner SJ, Sleeper LA, et al. Cerebrovascular accidents in sickle cell disease: rates and risk factors. Blood. 1998;91(1):288-94. 